Os artigos dos Textos para Discussão da Escola de Economia de São Paulo da Fundação Getulio Vargas são de inteira responsabilidade dos autores e não refletem necessariamente a opinião da FGV-EESP. É permitida a reprodução total ou parcial dos artigos, desde que creditada a fonte.

Escola de Economia de São Paulo da Fundação Getulio Vargas FGV-EESP www.eesp.fgv.br 


\title{
A coordination approach to the essentiality of money*
}

\author{
Luis Araujo ${ }^{\dagger} \quad$ Bernardo Guimaraes ${ }^{\ddagger}$
}

February 9, 2015

\begin{abstract}
The essentiality of money is commonly justified on efficiency grounds. In this paper, we propose an alternative view on the essentiality of money. We consider an economy with limited monitoring where agents have to coordinate on the use of two alternative technologies of exchange, money and credit. We show that although credit strictly dominates money from an efficiency perspective, money is essential for coordination reasons. If agents are patient, the region of parameters where they coordinate in the use of money strictly contains the region of parameters where they coordinate in the use of credit.
\end{abstract}

Key Words: Money, Credit, Beliefs, Coordination.

JEL Codes: E40, D83

\section{Introduction}

Monetary theorists justify the relevance of money on efficiency grounds, i.e., money matters because it is necessary to achieve socially desirable allocations. An implication of this view is that a model where money is essential requires limitations on agents' abilities to monitor each other. ${ }^{1}$ It is still an open question though the extent of the limitations on monitoring which are necessary to render money relevant. For instance, in order to ensure that money is essential, models of money which

${ }^{*}$ We would like to thank Braz Camargo, Tai-Wei Hu, Neil Wallace, and Randy Wright as well as various seminar and conference participants, for their comments and suggestions. Both authors gratefully acknowledge financial support from CNPq.

†São Paulo School of Economics-FGV, and Michigan State University, Department of Economics. Corresponding author: luis.fernando.araujo@fgv.br and araujolu@msu.edu.

${ }^{\ddagger}$ São Paulo School of Economics-FGV.

${ }^{1}$ Kocherlakota (1998) shows that any monetary allocation can be replicated by a monitoring technology which keeps track of past actions. Kocherlakota and Wallace (1998), and Cavalcanti and Wallace (1999) obtain that money is essential if monitoring is sufficiently limited. A relatively recent trend of papers based on Lagos and Wright (2005) combine money and credit as media of exchange. Examples are Berentsen et al (2008), Telyukova and Wright (2008), Sanches and Williamson (2010), and Williamson (2012). 
serve as workhorse to much work on monetary theory, such as Kiyotaki and Wright (1993), Trejos and Wright (1995), Shi (1995), and Lagos and Wright (2005), simply assume that agents cannot monitor each other.

In this paper, we propose an alternative rationale for the relevance of money. We argue that even if money is dominated in terms of efficiency by an alternative mechanism of exchange, labeled credit, money is still essential for coordination reasons. Our main result is that if agents are patient enough, they coordinate in the use of money in a region of parameters which strictly contains the region of parameters where they coordinate in the use of credit.

We start with a decentralized economy where autarky is the only equilibrium outcome in the absence of money or monitoring, the latter being modeled as a technology which allows an agent to observe the most recent action of his current partner. We show that, in the presence of monitoring, there exists a credit arrangement which is superior to money in terms of efficiency. While the economy with money but without monitoring is only able to achieve a sub-optimal allocation, the economy with monitoring but without money achieves the first best. Moreover, credit is an equilibrium in a larger region of parameters than the one necessary for money to be an equilibrium.

The problem with both money and credit is that each requires a particular coordination of beliefs. As a result, if agents are free to form any belief as to what other agents will do, a failure to coordinate can lead to autarky. In this paper, we are interested in the following question: which mechanism of exchange, money or credit, is less likely to be disrupted by a coordination failure? To deal with this question, we need to relax the assumption that agents are always free to form any belief as to what other agents will do. We do so by assuming that the economy experiences different states over time and there are remote states where beliefs are coordinated in a particular way. ${ }^{2}$ We first consider the economy with money but without monitoring and assume that there are remote states where agents always accept money and remote states where they never do so. We then consider the economy with monitoring but without money and assume that there are remote states where agents always engage in a credit exchange and states where they never do so. The idea is to use the existence of the remote states to pin down rationalizable outcomes in states which are not remote.

We first show that, irrespective of the mechanism of exchange, there is a unique rationalizable outcome: either exchange always take place, or it never takes place. Whichever outcome emerges depends on the fundamentals of the economy. More interestingly, we obtain that if agents are

\footnotetext{
${ }^{2}$ The existence of dominant regions is important for equilibrium selection in the literature on dynamic coordination games (e.g., Frankel and Pauzner (2000) and Burdzy, Frankel, and Pauzner (2001)) and in the global games literature (e.g., Morris and Shin (2003)).
} 
patient, the region of parameters where exchange always takes place under money strictly contains the region of parameters where exchange always takes place under credit. The broader message we want to convey is that coordination reasons may render money-like objects necessary even in environments where credit-like arrangements are feasible and superior to money from an efficiency point of view. That is, the resilience of money may be simply due to the fact that it is relatively easy to coordinate in its use.

Our paper is closely related to Araujo and Guimaraes (2014), which also consider coordination in the use of money in a decentralized economy along the lines of the economy considered here. We complement their paper by introducing monitoring and a credit arrangement and by comparing money and credit both in terms of efficiency and in terms of coordination. Finally, Camera and Casari (2014) and Duffy and Puzzello (2014) obtain experimental evidence which emphasizes the role of money as a coordinating device, i.e., money is used even if it is dominated by social norms of cooperation such as gift-exchange.

The paper is organized as follows. In the next section, we present the benchmark environment and we show that the presence of monitoring allows to achieve better allocations than the ones achieved with money. In section 3, we present the general environment and characterize rationalizable outcomes under credit and rationalizable outcomes under money. Section 4 compares credit and money, and section 5 concludes.

\section{Benchmark environment}

Time is discrete and the economy is populated by a unit continuum of agents with a common discount factor $\beta \in(0,1)$. To motivate a need for exchange, we assume that an agent likes the good produced by any other agent but he does not like the good he produces himself. We introduce trade frictions by assuming that agents meet in pairs and at most one good can be produced in a meeting. For tractability, we let goods be indivisible, with the utility of consumption given by $u$, and the cost of production given by $c$, with $\beta u>c$.

At any point in time an agent is either passive or active. Passive agents make no choice while active agents choose between committing $(C)$ and not committing $(\bar{C})$ to produce if called upon to do so in a given meeting. The status of an agent as passive or active depends on the technology of exchange. We consider two alternative technologies: credit and money.

Money There exists a storable and intrinsically useless object, labeled money. For tractability, we assume that money is indivisible and agents are constrained to hold at most one unit of money 
at a time. An agent is passive if he holds money, and he is active otherwise. Agents randomly meet among themselves. No transaction takes place in meetings between two active agents or between two passive agents. In any meeting between an active and a passive agent, the outcome depends on the action of the active agent. Formally, the outcome is determined by a function $f_{m}:\{C, \bar{C}\} \rightarrow\{P, \bar{P}\}$, where $P$ denotes production in exchange for money and $\bar{P}$ denotes no production and no exchange of money. A money mechanism is a function $f_{m}$ such that $f_{m}(C)=P$ and $f_{m}(\bar{C})=\bar{P}$. The requirement $f_{m}(\bar{C})=\bar{P}$ ensures that an active agent can always avoid production by choosing $\bar{C}$. In the first period, half of the population starts with money, while the remaining agents start with no money.

Credit There exists a monitoring technology which allows an agent to observe the record of his partner, i.e., a label $g$ (good) or $b$ (bad), which reflects the action $C$ (respectively, $\bar{C}$ ) in the previous period. An agent is passive if he has a record, and he is active otherwise. Active agents randomly meet passive agents. In a meeting, the outcome depends on the action of the active agent and the record of the passive agent. Formally, the outcome is determined by a function $f_{c}:\{C, \bar{C}\} \times\{g, b\} \rightarrow\{P, \bar{P}\}$, where $P$ denotes production and $\bar{P}$ denotes no production. A credit mechanism is a function $f_{c}$ such that $f_{c}(C, g)=P$ and $f_{c}(\bar{C}, g)=f_{c}(\bar{C}, b)=f_{c}(C, b)=\bar{P}$. The requirement $f_{c}(\bar{C}, g)=f_{c}(\bar{C}, b)=\bar{P}$ ensures that an active agent can always avoid production by choosing $\bar{C}$. In turn, the requirement $f_{c}(C, b)=\bar{P}$ allows an active agent to punish a passive agent with a bad record, while still keeping a good record himself. In the first period, half of the population starts with a good record, while the remaining agents start with no record.

Comment Our notion of credit requires some justification. In general, in a credit transaction, the creditor delivers a good to the debtor in exchange for a promise of obtaining a good in the future. In our setting, we capture this promise with the idea that the creditor acquires a good label which entitles him the right to consume a good in the future. The difference from usual credit transactions is that the promise does not need to be redeemed with the original debtor but it can be redeemed with any other agent in the economy. In this sense, it is like a multilateral credit arrangement, supported by the monitoring technology. It should be clear though that, even if one models credit transactions as bilateral arrangements, a monitoring technology would still be necessary. Indeed, what prevents a debtor from defaulting on his debt is the threat of future exclusion from credit transactions, a threat that is only credible if there exists a technology which 
releases information about bilateral transactions to third-part agents. ${ }^{3}$

\subsection{Equilibrium}

For each technology of exchange, we consider an equilibrium where active agents always choose $C$, on and off the equilibrium path. We start with the case of money and then look at the case of credit.

Money Let $V_{1}$ be the value function of a passive agent and $V_{0}$ be the value function of an active agent. If active agents always choose $C$ in meetings with passive agents, we have

$$
V_{1}=\frac{1}{2} \beta V_{1}+\frac{1}{2}\left(u+\beta V_{0}\right)
$$

and

$$
V_{0}=\frac{1}{2}\left(-c+\beta V_{1}\right)+\frac{1}{2} \beta V_{0} .
$$

Consider the expression for $V_{1}$. If a passive agent meets another passive agent, no trade happens. If a passive agent meets an active agent, he obtains utility $u$, and becomes an active agent in the following period. Consider now the expression for $V_{0}$. If an active agent meets a passive agent, he produces, receives money, and becomes a passive agent in the following period. If an active agent meets another active agent, no trade happens. It is optimal to choose $C$ in meetings with passive agents iff

$$
-c+\beta V_{1}>\beta V_{0},
$$

which can be rewritten as

$$
\frac{\beta}{2}(u+c)>c
$$

In turn, the expected welfare is

$$
W=\frac{u-c}{4(1-\beta)} .
$$

Credit On the equilibrium path, the payoff of an active agent who chooses $C$ is

$$
-c+\beta u-\beta^{2} c+\beta^{3} u+\ldots
$$

while a one-shot deviation to $\bar{C}$ implies

$$
0+\beta 0-\beta^{2} c+\beta^{3} u+\ldots
$$

\footnotetext{
${ }^{3}$ An example of this monitoring technology is the credit bureau, i.e., an institution which keeps track of consumers' credit histories in order to sell them to prospective lenders (Kandori, 1992, page 73).
} 
A deviation implies no cost of production in the current period (and the acquisition of a bad label), no utility of consumption in the following period (due to the bad label), and a return to the payoff of an active agent on the equilibrium path from the next period on. An active agent does not deviate if and only if

$$
\beta u>c
$$

which is always true. Off the equilibrium path, i.e., if an active agent meets a passive agent with bad label, he strictly prefers to choose $C$ because he incurs no current cost and he still keeps a good label.

Finally, the expected welfare is

$$
W=\frac{u-c}{2(1-\beta)},
$$

which is strictly larger than the welfare under money.

We assumed that the label of a passive agent is only based on his action in the previous period. Assume, instead, that the label of an agent is a function of his actions in all previous periods, and the actions of all agents with whom he has had a direct or an indirect contact. This information is akin to Kocherlakota's (1998) definition of memory. In this case, a deviation from the equilibrium path can be punished with permanent exclusion from consumption. Thus, an active agent does not deviate iff

$$
-c+\beta u-\beta^{2} c+\beta^{3} u+\ldots>0,
$$

i.e.,

$$
\beta u>c
$$

which is the same condition as in the case where the record of a passive agent only includes his last period action. Thus, at least as it refers to efficiency, the monitoring technology that we consider cannot be improved upon.

Summarizing, we have shown that irrespective of the mechanism of exchange, there exists an equilibrium where agents choose $C$ and exchange occurs whenever feasible. We have also shown that the credit equilibrium dominates the money equilibrium in two aspects. First, it occurs in a larger region of parameters. Second, it produces a higher welfare.

\section{General environment}

In the benchmark environment, there is always an autarkic equilibrium in which an active agent chooses $\bar{C}$ because he believes that all other agents will do the same. Thus, a particular coordination 
of beliefs is necessary if exchange is to take place. In what follows, we extend our benchmark environment to compare money and credit in terms of their ability to provide the coordination of beliefs which is required for exchange to happen.

We proceed as follows. Assume that, in any given period, the economy is in some state $z \in \mathbb{R}$. The economy starts at $z=0$ and the state changes according to a random process $z_{t+1}=z_{t}+\Delta z_{t}$, where $\Delta z_{t}$ follows a continuous and symmetric probability distribution that is independent of $z$ and $t$, with expected value $\mathrm{E}(\Delta z)=0$ and variance $\operatorname{Var}(\Delta z)>0$. We assume that active agents coordinate on a particular action if the state $z$ is either sufficiently large or sufficiently small. Precisely, there exists a state $\widehat{z}$ such that active agents always choose $C$ if $z>\widehat{z}$ and always choose $\bar{C}$ if $z<-\widehat{z}$. In states $z \in[-\widehat{z}, \widehat{z}]$, active agents are free to choose between $C$ and $\bar{C}$. We consider think of $\widehat{z}$ as an arbitrarily large real number.

In what follows, we maintain an agnostic view as to what may drive the existence of remote states, and justify their existence as follows: if a given mechanism of exchange can only be sustained if agents have to coordinate on it in every possible state, no matter how unlikely the state is, then this mechanism is tenuous. The assumption of these remote states provides a way to examine the robustness of different mechanisms of exchange.

It is easy to think of states where agents would choose not to produce in exchange for money (say, a hyperinflation) or for a good credit record (say, the monitoring technology does not work) and there are plausible scenarios were agents might find exceedingly costly to produce or trade. We discuss at the end of Section 4 what happens if we assume the existence of only one dominant region where agents choose $\bar{C}$ if $z<-\widehat{z}$.

\subsection{Coordination in the use of money}

Araujo and Guimaraes (2014) study coordination in the use of money in an environment which is similar to the one considered here. In particular, it delivers exactly the same value functions for agents with money and agents without money. ${ }^{4}$ As a result, the proof on the characterization of the region of parameters where agents always coordinate in the use of money is exactly the same. In what follows, we provide a sketch of the proof and refer to Araujo and Guimaraes (2014) for a complete proof.

Proposition 1 Let $\varphi(t)$ denote the probability that any state $z^{\prime}>z$ is reached at time $s+t$ and

\footnotetext{
${ }^{4}$ Araujo and Guimaraes (2104) assume that money is initially distributed to a measure $m$ of agents, while here we assume that $m=\frac{1}{2}$. This choice is natural since it produces the highest rate trade meetings, i.e., meetings between agents with money and agents without money.
} 
not before, conditional on the agent being in state $z$ in period $s$. Then, agents always coordinate in the use of money in the region $z \in[-\widehat{z}, \widehat{z}]$ if

$$
\sum_{t=1}^{\infty} \beta^{t} \varphi(t) \frac{u+c}{2}>c
$$

and they never do so if the inequality is reversed.

A sketch of the proof runs as follows. We use an induction argument, where at each step strictly dominated actions are eliminated. We start with the problem of an active agent in a meeting with a passive agent if the current state is $\widehat{z}$ and the current period is $s$. Remember that, by assumption, agents always choose $C$ in states $z>\widehat{z}$. Araujo and Guimaraes (2014, Lemma 1) show that the incentives to produce in exchange for money increase in the likelihood that money will be accepted in the future. Thus, the belief that all the other agents are following a cut-off strategy at state $\widehat{z}^{5}$ is the most pessimistic belief an agent may hold about the acceptability of money. That is, if an agent is willing to produce in exchange for money under this pessimistic belief, he is also willing to do so under any other belief.

Araujo and Guimaraes (2014, Lemmas 2 and 3) then show that, if an agent believes all the other agents are following a cut-off strategy at some state $z$, then his expected payoff if he follows the same cut-off strategy is sufficient to determine the optimal behavior in state $z$. Applied to the problem of the agent in state $\widehat{z}$, this result implies that an agent strictly prefers to choose $C$ in state $\widehat{z}$ if

$$
-c+\sum_{t=1}^{\infty} \beta^{t} \varphi(t) \int_{\widehat{z}}^{\infty} V_{1, z^{\prime}} d F\left(z^{\prime} \mid t\right)>\sum_{t=1}^{\infty} \beta^{t} \varphi(t) V_{0, z^{\prime}} d F\left(z^{\prime} \mid t\right)
$$

where $V_{1, z^{\prime}}\left(V_{0, z^{\prime}}\right)$ is the value of one unit (zero units) of money in state $z^{\prime}$. The left hand side is the expected continuation payoff of choosing $C$ against a passive agent with a good label. It is given by the current $\operatorname{cost} c$, plus the future benefit of holding money. In turn, the latter is given by the discounted probability that the first time the economy reaches some state $z^{\prime}>z$ after period $s$ happens in period $s+t$, which is given by $\beta^{t} \varphi(t)$ multiplied by the expected value of $V_{1, z^{\prime}}{ }^{6}$ The right hand side is the future benefit of not holding money.

The value of having money in some state $z^{\prime}>\widehat{z}$ is given by

$$
V_{1, z^{\prime}}=\frac{1}{2} \beta \int_{-\infty}^{+\infty} V_{1, z^{\prime \prime}} d G\left(z^{\prime \prime} \mid z^{\prime}\right)+\frac{1}{2}\left[u+\beta \int_{-\infty}^{+\infty} V_{0, z^{\prime \prime}} d G\left(z^{\prime \prime} \mid z^{\prime}\right)\right]
$$

\footnotetext{
${ }^{5}$ If an agent follows a cut-off strategy at state $\widehat{z}$, he only produces in exchange for money in states $z \geq \widehat{z}$.

${ }^{6}$ The cdf of $z^{\prime}$ is given by $F\left(z^{\prime} \mid t\right)$, i.e., the probability that the state of the economy is below or equal to $z^{\prime}$ conditional on the event that the first time the economy reaches some state $z^{\prime}>\widehat{z}$ after period $s$ happens in period $s+t$.
} 
while the value of not having money is

$$
V_{0, z^{\prime}}=\frac{1}{2}\left[-c+\beta \int_{-\infty}^{+\infty} V_{1, z^{\prime \prime}} d G\left(z^{\prime \prime} \mid z^{\prime}\right)\right]+\frac{1}{2} \beta \int_{-\infty}^{+\infty} V_{0, z^{\prime \prime}} d G\left(z^{\prime \prime} \mid z^{\prime}\right),
$$

where $G\left(z^{\prime \prime} \mid z^{\prime}\right)$ is the probability that the current state is $z^{\prime \prime}$ conditional on the previous state being $z^{\prime}$. Note that, even though the integrals in the expressions above are quite complicated objects, $V_{1, z^{\prime}}-V_{0, z^{\prime}}$ is equal to $\frac{1}{2}(u+c)$. Thus, substituting $V_{1, z^{\prime}}$ and $V_{0, z^{\prime}}$ in $(2)$, we obtain that an agent strictly prefers to choose $C$ in state $\widehat{z}$ if

$$
\sum_{t=1}^{\infty} \beta^{t} \varphi(t) \frac{1}{2}(u+c)>c
$$

which corresponds to (1).

The last part of the proof uses continuity on $z$ to obtain that there exists some $\epsilon$ such that active agents strictly prefer to choose $C$ in all states $z>\widehat{z}-\epsilon$. This implies that the most pessimistic belief an agent may hold about the acceptability of money is now given by the belief that all other agents are following a cut-off strategy at $\widehat{z}-\epsilon$. As a result, the problem (thus, the optimal choice) of an active agent in a meeting with a passive agent with a good label if the current state is $\widehat{z}-\epsilon$ is exactly the same problem (thus, the same optimal choice) if the current state is $\widehat{z}$. Proceeding this way, we can iteratively iterate and thus eliminate choosing $\bar{C}$ as a strictly dominated action until we reach reach the state $-\widehat{z}$. This implies that $C$ is the only rationalizable action in states $z \in[-\widehat{z}, \widehat{z}]$. Finally, an analogous reasoning applies if the reverse of (1) holds. In this case, $\bar{C}$ is the only rationalizable action for all $z \leq \widehat{z}$.

\subsection{Coordination in the use of credit}

Consider the problem of an active agent in state $z \in[-\widehat{z}, \widehat{z}]$ in period $t$, under the belief that all active agents in period $t+1$ will be willing to choose $C$ if and only if $z_{t+1} \in Z$, where $Z$ is some set which contains all states $z>\widehat{z}$. Remember that, by assumption, agents always choose $C$ in states $z>\widehat{z}$. If the agent chooses $C$, he obtains

$$
-c+\beta \int_{-\infty}^{+\infty} \chi_{z^{\prime} \in Z} u d G\left(z^{\prime} \mid z\right)+\beta^{2} \int_{-\infty}^{+\infty} \int_{-\infty}^{+\infty} V\left(z^{\prime \prime}\right) d F\left(z^{\prime \prime} \mid z^{\prime}\right) d G\left(z^{\prime} \mid z\right),
$$

where $\chi_{z^{\prime} \in Z}=1$ if $z^{\prime} \in Z$ and $V\left(z^{\prime \prime}\right)$ is the value of an active agent two periods ahead in state $z^{\prime \prime}$. In turn, if he chooses $\bar{C}$, he obtains

$$
\beta^{2} \int_{-\infty}^{+\infty} \int_{-\infty}^{+\infty} V\left(z^{\prime \prime}\right) d F\left(z^{\prime \prime} \mid z^{\prime}\right) d F\left(z^{\prime} \mid z\right)
$$


Observe that, since labels only last for one period, the last term in (3) coincides with (4). Thus, the net value of choosing $C$ in state $z$ is given by

$$
-c+\beta u \int_{-\infty}^{+\infty} \chi_{z^{\prime} \in Z} d F\left(z^{\prime} \mid z\right),
$$

and it only depends on the fundamentals and on the set $Z$. This implies that active agents' decisions are strategic complements, i.e., if $Z^{A}$ and $Z^{B}$ are such that $Z^{A} \subset Z^{B}$, then the incentives to choose $C$ given $Z^{B}$ are strictly larger than the incentives to choose $C$ given $Z^{A}$.

We can now prove our result. As in the case with money, the proof uses an induction argument, where at each step strictly dominated actions are eliminated. We start with the problem of an active agent in a meeting with a passive agent if the current state is $\widehat{z}$ and the current period is $s$. Since the distribution of $\Delta z$ is symmetric, the probability the economy will be at a state $z>\widehat{z}$ next period is $\frac{1}{2}$. Suppose an agent believes nobody will be willing to produce in the next period if $z<\widehat{z}$. Since active agents' decisions are strategic complements, this is the worst scenario to choose $C$. Using (5), it is optimal to produce at $\widehat{z}$ if and only if

$$
-c+\frac{1}{2} \beta u>0
$$

As in the case with money the last part of the proof uses continuity on $z$ to obtain that there exists some $\epsilon$ such that active agents strictly prefer to choose $C$ in all states $z>\widehat{z}-\epsilon$. In consequence, once choosing $\bar{C}$ has been ruled out for all $z \geq \widehat{z}$, the choice $C$ becomes a strictly dominant action for an agent in any state $z>\widehat{z}-\epsilon$. But then if $-c+\frac{1}{2} \beta u>0$, an active agent finds it strictly optimal to choose $C$ in state $z=\widehat{z}-\epsilon$. Proceeding this way, we can iteratively iterate and thus eliminate choosing $\bar{C}$ as a strictly dominated action until we reach reach the state $-\widehat{z}$. This implies that $C$ is the only rationalizable outcome in states $z \in[-\widehat{z}, \widehat{z}]$. An analogous reasoning applies if $-c+\frac{1}{2} \beta u<0$. In this case, $\bar{C}$ is the only rationalizable action for all $z \leq \widehat{z}$. Proposition 1 summarizes our result.

Proposition 2 Agents always coordinate in the use of credit if

$$
\frac{\beta u}{2}>c
$$

and they never do so if the inequality is reversed.

Note that the value of $\widehat{z}$ does not enter in (1) and (6). The existence of dominant regions affects agents' behavior in $[-\widehat{z}, \widehat{z}]$ but it does not matter how remote these regions are. 


\section{$4 \quad$ Money and credit}

In the benchmark environment credit dominated money because we assumed away coordination problems and only focused on the efficiency properties of the mechanisms of exchange. In the general environment, though, there is a trade-of between efficiency and coordination. That is, the fact that credit is better than money does not ensure that agents can coordinate on it better. It fact, if agents are patient, they can coordinate better on money.

Formally, combining Propositions 1 and 2, we obtain that agents coordinate in the use of money but do not coordinate in the use of credit iff

$$
\sum_{t=1}^{\infty} \beta^{t} \varphi(t) \frac{1}{2}(u+c)>c>\frac{1}{2} \beta u .
$$

Since $\sum_{t=1}^{\infty} \beta^{t} \varphi(t)\left(\frac{u+c}{2}\right)$ converges to $\frac{u+c}{2}$ when $\beta$ converges to one, there exists $\beta^{*}$ such that, for all $\beta>\beta^{*}$, agents can coordinate in the use of money but they cannot coordinate in the use of credit. Figure 1 shows the regions of parameters in which money and credit are an equilibrium in the benchmark and in the general environment. ${ }^{7}$ The dotted curves depict the condition for existence of equilibrium in the benchmark model and the solid curves show the condition for coordination in the general environment. The cases with money are depicted with circles and the cases with credit are depicted with asterisks. In the benchmark model, autarky is the unique equilibrium in the region below the dotted curves, and there are multiple equilibria above the dotted curves. In the general environment, agents always coordinate in the use of the medium of exchange above the solid curves and never do so below the solid curves.

Patient agents are willing to produce in exchange for money as long as they believe that they will be able to eventually spend the money. That is, although the belief that money may be accepted in the near future matters, acceptability in later periods is also important. This makes it easier to coordinate in the use of money. Intuitively, if an agent believes that eventually he will find another agent who accepts money, he is willing to produce in exchange for money even if he believes that a large number of his future partners will not accept money. In contrast to money, since labels only last for one period, coordination on credit critically depends on the belief that credit will be "spent" in the near future. As a result, agents can only coordinate on credit if the primitives of the economy compensate for the belief that, while the disutility of production is certain, the benefit of acquiring the good label is short lived.

What if we remove the assumption that agents always choose $C$ if $z>\widehat{z}$ ? In this case, autarky

\footnotetext{
${ }^{7}$ We consider a normal process assuming $\mathrm{E}(\Delta z)=0$. The probabilities $\varphi(t)$ are obtained from Monte Carlo simulations (they do not depend on the variance $\operatorname{Var}(z))$.
} 


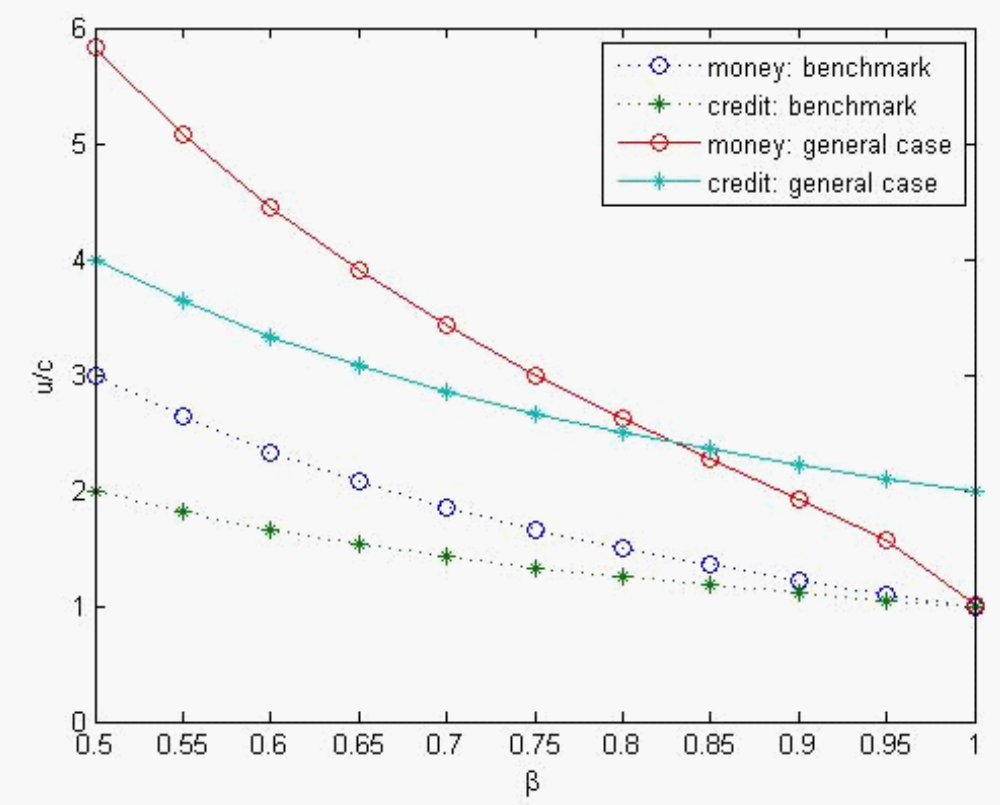

Figure 1: Money and credit in the benchmark and general environments

is always an equilibrium. Still, the existence of the region where agents always choose $\bar{C}$ implies autarky is the unique equilibrium when $u / c$ is below the respective solid line in Figure 1. Hence, when $\beta$ is large, there is a range of values for $u / c$ in which money is essential from a coordination point of view (although credit would be more efficient). As long as we are willing to assume the existence of states where production will not be possible or desirable for the active agent, for large values of $\beta$, it is easier to coordinate on money.

\section{$5 \quad$ Final remarks}

We showed that if agents are patient, the region of parameters where they coordinate in the use of money is strictly larger than the region of parameters where they coordinate in the use of credit. Thus coordination reasons may render money relevant even in environments where credit is feasible and superior to money from an efficiency point of view.

In order to render our model tractable, we made some assumptions that deserve discussion. First, we assumed that money is indivisible and that agents can hold at most one unit of money at a time. This assumption follows earlier models of money and search, i.e., Kiyotaki and Wright (1989, 1993), Trejos and Wright (1995), and Shi (1995). Lagos and Wright (2005) consider a model where agents participate in a centralized Walrasian market in every period, which allows to introduce 
divisible money in a tractable way. The difficulty with introducing divisible money is that is breaks the simple dichotomy between accepting money and not accepting money which greatly simplified our analysis. Besides, the introduction of periodic access to a centralized Walrasian market has non-trivial implications on coordination, and it is not clear from the outset whether it constitutes a better benchmark than the one considered here, with fully decentralized trade. Finally, what our results show is that the key feature of money that facilitates coordination in its use is the fact that it is a permanent record of past transactions, a feature that does not depend on its divisibility.

We assumed that credit is sustained by a monitoring technology which only records the last period action of an agent. This way, we obtain that while the current payoff of a passive agent depends on his history, the optimal action of an active agent does not depend on his history. The analysis would become much more involving if an active agent anticipates that his current action will impact his optimal action the next time he is called upon to choose again. Clearly, the choice of a one-period monitoring technology matters for our results, and it cannot be defended only on grounds of tractability. Indeed, the difficulty to coordinate on credit comes exactly from the fact that labels are short-lived. The way in which we attempted to overcome this issue is by considering a benchmark where the superiority of credit over money does not depend on the amount of information the technology is able to record. That is, for efficiency reasons, one-period monitoring suffices. This makes it clear that increasing the amount of information in the recordkeeping technology may only be meaningful for coordination reasons, thus reinforcing the message that agents are better able to coordinate on money because money is a permanent record of past transactions.

\section{References}

[1] Araujo, L. and Guimaraes, B., 2014, Coordination in the use of money, Journal of Monetary Economics 64, 38-47.

[2] Berentsen, A., G. Camera and C. Waller., 2008. Money, Credit and Banking, Journal of Economic Theory, 135, 171-195.

[3] Burdzy, K., Frankel, D., and Pauzner A., 2001, Fast Equilibrium Selection by Rational Players Living in a Changing World, Econometrica 68, 163-190.

[4] Camera, G. and Casari, M., 2014, The coordination value of monetary exchange: Experimental evidence, American Economic Journal: Microeconomics 6, 290-314. 
[5] Cavalcanti, R., A. Erosa, and T. Temzelides, 1999, Private Money and Reserve Management in a Random Matching Model, Journal of Political Economy 107:5, 929-945.

[6] Cavalcanti, R. and N. Wallace, 1999, A Model of Private Bank-Note Issue, Review of Economic Dynamics, 2:1 January, 104-136.

[7] Duffy, J. and Puzzello, D., 2014, Gift-exchange versus monetary exchange: theory and evidence, American Economic Review 104, 1735-1776.

[8] Frankel, D. and Pauzner, A., 2000, Resolving indeterminacy in dynamic settings: the role of shocks, Quarterly Journal of Economics 115, 283-304.

[9] Kandori, M., 1992, Social Norms and Community Enforcement, Review of Economic Studies, $59,63-80$.

[10] Kiyotaki, N. and R. Wright, 1989, On Money as a Medium of Exchange, Journal of Political Economy, 97, 927-954.

[11] Kiyotaki, N. and R. Wright, 1993, A Search-Theoretic Approach to Monetary Economics, American Economic Review 83, 63-77.

[12] Kocherlakota, N., 1998, Money is Memory, Journal of Economic Theory, 81, 232-51.

[13] Kocherlakota, N. and N. Wallace, 1998, Incomplete Record-Keeping and Optimal Payment Arrangements, Journal of Economic Theory, 81, 272-289.

[14] Lagos, R., Wright, R., 2005. A unified framework for monetary theory and policy analysis. Journal of Political Economy 113, 463-484.

[15] Morris, S. and Shin, H., 2003, Global games: theory and applications, in Advances in Economics and Econometrics (Proceedings of the Eighth World Congress of the Econometric Society), edited by M. Dewatripont, L. Hansen and S. Turnovsky; Cambridge University Press.

[16] Sanches, D. and S. Williamson, 2010, Money and Credit with Limited Commitment and Theft, Journal of Economic Theory, 145, 1525-1549.

[17] Shi, S., 1995, Money and Prices: A Model of Search and Bargaining, Journal of Economic Theory 67, 467-496.

[18] Telyukova, I. and R. Wright, 2008, A Model of Money and Credit, with Application to the Credit Card Debt Puzzle, Review of Economic Studies 75, 629-647. 
[19] Trejos, A. and R. Wright, 1995, Search, Bargaining, Money, and Prices, Journal of Political Economy, 103, 118-141.

[20] Wallace, N., 2001, Whither Monetary Economics?, International Economic Review, 42, 847869.

[21] Williamson, S., 2012, Liquidity, Financial Intermediation, and Monetary Policy in a New Monetarist Model, American Economic Review, 102, 2570-2605. 